\title{
Using Enterprise Architecture to Integrate Lean Manufacturing, Digitalization, and Sustainability: A Lean Enterprise Case Study in the Chemical Industry
}

\author{
Ming-Hui Liao * and Chi-Tai Wang
}

check for

updates

Citation: Liao, M.-H.; Wang, C.-T. Using Enterprise Architecture to Integrate Lean Manufacturing, Digitalization, and Sustainability: A Lean Enterprise Case Study in the Chemical Industry. Sustainability 2021, 13, 4851. https://doi.org/10.3390/ su13094851

Academic Editor: Grigorios

L. Kyriakopoulos

Received: 19 February 2021

Accepted: 23 April 2021

Published: 26 April 2021

Publisher's Note: MDPI stays neutral with regard to jurisdictional claims in published maps and institutional affiliations.

Copyright: (C) 2021 by the authors Licensee MDPI, Basel, Switzerland. This article is an open access article distributed under the terms and conditions of the Creative Commons Attribution (CC BY) license (https:// creativecommons.org/licenses/by/ $4.0 /)$.
Graduate Institute of Industrial Management, School of Management, National Central University, Taoyuan City 32001, Taiwan; ctwang@mgt.ncu.edu.tw

* Correspondence: peterliao20171231@gmail.com

Abstract: The chemical industry has sustained the development of global economies by providing an astonishing variety of products and services, while also consuming massive amounts of raw materials and energy. Chemical firms are currently under tremendous pressure to become lean enterprises capable of executing not only traditional lean manufacturing practices but also emerging competing strategies of digitalization and sustainability. All of these are core competencies required for chemical firms to compete and thrive in future markets. Unfortunately, reports of successful transformation are so rare among chemical firms that acquiring the details of these cases would seem an almost impossible mission. The severe lack of knowledge about these business transformations thus provided a strong motivation for this research. Using The Open Group Architecture Framework, we performed an in-depth study on a real business transformation occurring at a major international chemical corporation, extracting the architecture framework possibly adopted by this firm to become a lean enterprise. This comprehensive case study resulted in two major contributions to the field of sustainable business transformation: (1) a custom lean enterprise architecture framework applicable to common chemical firms making a similar transformation, and (2) a lean enterprise model developed to assist chemical firms in comprehending the intricate and complicated dynamics between lean manufacturing, digitalization, and sustainability.

Keywords: lean enterprise; digitalization; sustainability; enterprise architecture; The Open Group Architecture Framework (TOGAF)

\section{Introduction}

The chemical industry plays a key role in the global economy. With annual sales of USD 5 trillion and a workforce of more than 20 million people, chemical manufacturing is the backbone of various end-market industries, including automobiles, construction, pharmaceutics, agriculture, etc. [1,2]. In addition to economic contributions, chemical firms also have a key role to play in pursuing various societal and sustainability goals. Especially through major initiatives such as Responsible Care and the Global Product Strategy, chemical companies have made significant progress in making products with renewable resources (that is, supporting a circular economy), improving chemical usage across the value chain, reducing greenhouse gas (GHG) emissions, and improving the sustainability of the food supply [3].

At present, chemical firms are facing a global market that is changing rapidly. In such a dynamic environment, technology is advancing at an exponential rate, along with increasingly higher customer expectations. Instead of pushing individual new products into the markets, developing integrated solutions has become a better strategy. Meanwhile, climate change, resource scarcity, and other global issues are driving firms to pursue innovation and differentiation so as to develop or maintain a unique competitive advantage. At the same time, these challenges are also new growth opportunities for chemical firms [4]. 
According to market research [5], three megatrends are expected to have a profound impact on the chemical industry in the coming years: sustainability and the circular economy, digitalization, and innovation and accelerated globalization. Especially, the first two megatrends are considered as the major force for enabling Chemistry 4.0 [6,7], that is, the fourth revolution of the chemical industry. (In the past, industrialization and coal chemistry enabled Chemistry 1.0, petrochemistry enabled Chemistry 2.0, and globalization and specialization enabled Chemistry 3.0.) With the industry currently undergoing a paradigm change in demand structure and public preference, digitalization and sustainability should soon become critically important strategies for chemical firms. Not long ago, there was a general belief among chemical firms that they could either focus on making a profit or concentrate on caring about the world. Today, many believe that they have to do both; it means doing well (focusing on profit) will go together with doing good (improving the world). So a purpose-led chemical company will balance the need to generate profitable growth with the need to make a positive contribution to the world, because "we cannot be successful, nor can we call ourselves successful, in a society that fails" [8].

The following depicts how the chemical industry should change for the future (with the application of Peter Drucker's "paradigm of change" model [9]). It consists of three elements: is, will, and should. The business transformation needs to find a balance between the three:

- What is the business? Operations: Traditional (or the firm's traditional state of existence at present). The chemical industry's traditional focus is lean manufacturing and continuous improvement by concentrating on organizational strengths.

- What will the business be? Tactics: Transitional (or the firm's transitional state of existence for the future). As previously elaborated, this transition in the chemical industry can arguably be adopting digitalization to increase efficiency and drive growth by satisfying unmet consumer needs.

- What should the business be? Strategy: Transformational (or the firm's transformational state of existence). As elaborated in the following, this transformation for the chemical industry can be targeted at elevating chemical firms from simply conducting lean manufacturing to adopting lean enterprise practices in order to achieve higher standards (e.g., UN sustainability goals) by attracting new customers or successfully exploiting new product development.

A lean enterprise (LE) is a group of individuals, functions, and legally separated but operationally synchronized organizations [10]. With efficient administration and strong leadership integrated with $R \& D$, production, distribution, sales, customer service, and other business functions, an LE can rapidly identify promising opportunities from each value stream and extract the most value for customers. Interpreted according to current development trends in the global markets, an LE can be described as "a process-oriented, digitized value-adding network as well as the waste-free interaction of humans, organizational, and technical aspects in a fully interconnected and integrated system" [11]. This study intends to contribute to the development of the required knowledge, know-how, and tools to make LEs a common reality in the chemical industry. Enterprise architecture (EA) is used as the main research tool because it is a mature enterprise practice. The goal is to gain useful results for chemical firms to transform into lean enterprises, capable of simultaneously achieving lean manufacturing, digitalization, and international sustainability targets such as the United Nations Sustainable Development Goals (UNSDGs) [12]. Therefore, this study used EA methodology as the research tool to examine an actual case study of a major international chemical firm. The aim was to understand the EA framework or model for chemical firms to transform into LEs.

The remainder of this paper is organized as follows. In the next section, the challenges currently faced by chemical firms are stated in detail, followed by elaborations of corresponding strategies. In Section 3, a literature review is presented to cover the major components of this study: EA, sustainability, digitalization, and LE. The research methodology used to examine the case study is described in Section 4, and it is applied to a 
comprehensive study of a major international chemical firm in Section 5. Research findings and contributions are elaborated in Section 6. Finally, potential works to be considered for future research are described in Section 7.

\section{Challenges to Overcome and Paths to Take}

The chemical industry has experienced a long period of prosperity. Whether that prosperity will continue is mostly based on how well chemical firms can perform in three critical areas: (1) growth and innovation, (2) market performance and cost optimization, and (3) circular economy and sustainability [13]. Moreover, as suggested by Bartels et al. [14], the industry is currently on the brink of profound changes triggered by several disrupting forces:

- A circular economy, which replaces the traditional take-make-dispose way of life with the production of reusable and recyclable goods.

- Industrial recalibration, which refers to the use of digital technologies to increase manufacturing efficiency.

- Digitalization downstream, which means conducting end-to-end value chain digitalization to address consumer needs.

- Reworking work, which refers to deploying new workforce models to handle new types of work in the digital age.

These disrupting forces will bring serious challenges as well as brand new opportunities to the industry in the foreseeable future.

According to Digital McKinsey [15], a noticeable number of companies are attempting to change from making point solutions to delivering sustainable impact by adopting digital technologies. The following are strategies commonly adopted for such a campaign: (1) Establish a clear vision and a time-phased execution roadmap. (In reality, as many as $59 \%$ of manufacturers do not have such a vision and only $25 \%$ have finished some sort of pilot work to showcase potential benefits.) (2) Take every opportunity to remove operational pain points or create competitive edges. (However, over 50\% of manufacturers consider insufficient ROI as a major barrier to large-scale digital manufacturing.) (3) Resolve the capability gap. (This is because $69 \%$ of manufacturers consider talent as the number-one issue in their migration to digital manufacturing.) While posing serious challenges, these disruptive changes also bring new growth opportunities. For chemical firms, the biggest challenge is to really understand where their industry will prosper. After identifying where the industry will best operate, the focus then becomes constructing execution roadmaps and, more importantly, a well-thought enterprise architecture framework (or similar things) to provide a clear vision/guidance for the transformation journey.

As stated earlier, sustainability/circular economy, digitalization, and innovation/accelerated globalization are the megatrends that are currently shaping the future of the chemical industry [5]. To prepare for upcoming challenges, firms must at least reevaluate their product/service portfolios and adjust their business models accordingly. In addition, firms may also consider approaches such as enhancing certain sustainability efforts with digital technologies (e.g., measuring product environmental footprints, developing sustainable business models, or creating sustainable innovations) [16]. There are indeed success stories of using digital technologies; however, the technology also spurs cybercrime and compromises privacy. The more serious issue is that digital transformations are among the most difficult organizational transformations that firms can possibly engage in. To be more precise, in a market study by McKinsey \& Company [17], less than $25 \%$ of organizations report improved performance with digital transformations; moreover, only some of those improvements are long-lasting. Obviously, if digital transformations are to be done along with lean manufacturing and sustainability, the level of difficulty can only be higher.

Therefore, from a practical as well as a research point of view, it is worth the effort to study the convergence of these megatrends, in order to know better how one may influence the others. So far, studies have been conducted to uncover the knowledge in the convergence of two megatrends, e.g., digitalization and sustainability [18], which 
provides insights such as whether the growing application of digital technologies among chemical firms will foster a smoother transition toward sustainability for the industry. Nevertheless, almost no research has been done to explore the intricate dynamics among all three megatrends and their collective influence in shaping the future. The need for such knowledge is thus quite urgent.

In summary, there are research gaps in previous studies in how to develop a workable approach or model for business transformations and establish a clear vision with an execution roadmap, which involves lean manufacturing, digitalization, and sustainability. Therefore, the aims of this study require seeking answers to the following questions: (1) What LE architecture framework can be developed to integrate lean manufacturing, digitalization, and sustainability for the chemical industry in the future? (2) What is the LE model for the chemical industry to follow to realize the interaction and dynamic influence between lean manufacturing, digitalization, and sustainability?

Enterprise architecture (EA) is "an approach for managing the complexity of an organization's structures, business environments, different information systems, and for facilitating the integration of strategy, personnel, business, data, and information technology (IT)" [19]. From a different perspective, EA is "a well-defined practice for conducting enterprise analysis, design, planning, and implementation, using a comprehensive approach at all times, for the successful development and execution of strategy" [20]. By applying architecture principles and using the various aspects of an enterprise, EA and the associated governance systems offer a disciplined and proven logic for organizations to handle major tasks, motivating and guiding them to accomplish substantial changes in their business, processes, and IT [21]. Thus, the chemical industry could benefit from an EA developed to incorporate digitalization and sustainability in the industry's lean manufacturing business environment. Such a blueprint should be quite useful in helping chemical firms to become LEs, thus making them better prepared for future markets.

\section{Literature Review}

This section reviews the literature on EA, sustainability, digitalization, and LE in four subsections.

\subsection{Enterprise Architecture (EA)}

EA is aimed at giving an enterprise control over its complexity, processes and information systems, data demand, and interface analysis. EA creates a complete view of an enterprise, understood by all involved stakeholders, and supports the transfer of strategy to daily processes [22].

The following are EA frameworks discussed in [23]:

- The Zachman Framework is a pioneering work in this field, proposed by John Zachman in 1987. The framework is depicted as a bounded $6 \times 6$ "matrix" with $5 \mathrm{~W} 1 \mathrm{H}$ (what, how, where, who, when, and why) for six stakeholders (planner, owner, designer, builder, implementer, and participant) in an enterprise. The communication interrogatives are listed columns and the reification transformations in rows [24].

- $\quad$ The NATO Architecture Framework (NAF) provides a standard for developing and describing architectures for military and business use. NAF life cycle group activities are organized in eight stages: establish architecture landscape, establish architecture vision, describe alternatives of architecture, evaluate alternatives of architecture and propose trade-offs, develop and maintain migration plan, govern the application of architecture, decide on architecture changes, and manage architecture motivation data and dashboard [25].

- The University of Minnesota Framework applies a set of EA guiding principles: demonstrate value, promote stewardship, enhance transparency and communication, have conversations, reduce risk, and fortify compliance [26].

- The Department of Defense Architecture Framework (DoDAF) covers four enterprise views: operational, system, technical standards, and all views [27]. 
- The Federal Enterprise Architecture Framework (FEAF), developed by the US Federal Chief Information Officers Council [28], is based on the following items: primary outcomes, levels of scope, essential elements, sub-architecture domains, reference models, current and future views, transition plans, and a roadmap.

- $\quad$ The Treasury Enterprise Architecture Framework (TEAF) was published by the US Department of Treasury in July 2000 [29].

- The Open Group Architecture Framework (TOGAF) was developed by members of The Open Group who worked within the Architecture Forum [30]. TOGAF standards include a content framework to increase output consistency, created when using the Architecture Development Method (ADM) [31].

Companies select an EA framework based on their corporate objectives and industryspecific considerations. As revealed in the literature, TOGAF and FEAF are popular EA frameworks; their adoption rate in the public sector is $32 \%$ and $25 \%$, respectively [32]. Table 1 lists selected EA studies covering various business functions (e.g., strategy, IT, and technology development) in multiple industries (e.g., public sector, private enterprises, hospitals, universities, and airports).

Table 1. Selected EA research.

\begin{tabular}{lll}
\hline \multicolumn{1}{c}{ Subject } & \multicolumn{1}{c}{ Feature } & Reference \\
\hline $\begin{array}{l}\text { Integrated research for architecture-based } \\
\text { energy management in sustainable airport }\end{array}$ & $\begin{array}{l}\text { Use TOGAF ADM to propose EA for an energy } \\
\text { management information system in an airport }\end{array}$ & [33] \\
\hline $\begin{array}{l}\text { Architecture board practices in adaptive } \\
\text { enterprise architecture with digital platform: } \\
\text { case of a global healthcare enterprise }\end{array}$ & $\begin{array}{l}\text { Conduct digital transformations with adaptive } \\
\text { EA to align IT strategies and other related } \\
\text { elements for global health care enterprise }\end{array}$ & [34] \\
\hline $\begin{array}{l}\text { Hospital enterprise architecture framework } \\
\text { (study of Iranian University Hospital }\end{array}$ & $\begin{array}{l}\text { Use TOGAF to develop localized EA } \\
\text { framework for university hospital }\end{array}$ & [35] \\
\hline $\begin{array}{l}\text { Organization) } \\
\text { TOGAgning enterprise architecture based on }\end{array}$ & $\begin{array}{l}\text { Use TOGAF to develop EA for state-owned } \\
\text { enterprise in Indonesia }\end{array}$ & [36] \\
\hline $\begin{array}{l}\text { Enterprise Architecture: Key to Successful } \\
\text { Digital Business Transformation }\end{array}$ & $\begin{array}{l}\text { Use TOGAF ADM to develop EA for STMIK } \\
\text { (university in Indonesia) }\end{array}$ \\
\hline $\begin{array}{l}\text { Architecture framework of IoT-based food and } \\
\text { farm systems: multiple case study }\end{array}$ & $\begin{array}{l}\text { Develop architecture framework for IoT-based } \\
\text { systems in agriculture and food industries }\end{array}$ & [37] \\
\hline $\begin{array}{l}\text { Transformational and transactional factors for } \\
\text { successful implementation of enterprise } \\
\text { architecture in public sector }\end{array}$ & $\begin{array}{l}\text { Use organizational performance and change } \\
\text { theory to identify success factors for EA } \\
\text { implementation in South Korea's public sector }\end{array}$ \\
\hline
\end{tabular}

\subsection{Sustainability in the Chemical Industry}

In the 1970s and 1980s, several major chemical disasters occurred in different parts of the world, including the Seveso chemical accident in 1976, the Bhopal gas tragedy in 1984, and the Houston Chemical Complex explosion and Exxon Valdez oil spill in 1989. These human-made accidents inflicted tremendous damage on the economy, society, and environment. To regain the public's trust, chemical firms have taken various measures to ensure public safety and sustainable development [40]. The most frequently quoted definition for sustainable development is "development that meets the needs of the present without compromising the ability of future generations to meet their own needs" [41], and for sustainability is "the possibility that humans and other life will flourish on earth forever" [42].

Sustainability has gradually become a significant focus across the chemical industry, inspiring the establishment of many global initiatives. For example, Responsible Care is an initiative that started in Canada in 1984 and was implemented by the US chemical industry in 1988; at present, it is being followed in 68 economies worldwide [43]. Based on the principles of the UN Global Compact and Responsible Care, Together for Sustainability 
(TfS) is a joint effort by 25 chemical firms to establish de facto standards for the environmental, social, and governance (ESG) performance of the chemical supply chain [44]. The purpose of Chemie3 is to use sustainability as a guiding principle for the German chemical industry and enhance its contributions to sustainable development [45]. The Platform for Accelerating the Circular Economy (PACE) is an initiative that was launched during the 2018 World Economic Forum annual meeting to drive public and private actions on the circular economy [46]. Founded in 2019, the Alliance to End Plastic Waste (AEPW) is a global, cross-value-chain initiative that was formed to stop the disposal of plastic waste in the environment [47]. So far, more than 40 companies in the plastics and consumer goods value chain have committed over USD 1.0 billion to minimize plastic waste and promote post-use solutions. All of these are efforts that the chemical industry has been transforming to achieve the UNSDGs, which will, in turn, dramatically change the way of doing business not only for the benefit of the business itself but also for the environment and society.

The UNSDGs were launched in 2016 in an effort to end poverty, protect the planet, and ensure prosperity for all humanity. Each of the 17 UNSDGs has a specific target to be achieved by 2030, which can only be done with the united effort of governments, industries, civil societies, communities, and individuals [48]. In 2018, the chemical industry worked with the World Business Council for Sustainable Development (WBCSD) to explore the potential for chemical firms to contribute to the UNSDGs. The chemical sector can help advance each of the 17 SDGs in a range of different ways. However, to develop an interaction with this basic plan, the industry needs to prioritize what SDGs it has the most influence on or the most ability to drive innovation, transformation, and impact by leveraging its role in the value chain. WBCSD identified 10 goals as priority SDGs for the chemical sector [49] across the five themes (food, water, people and health, energy, and infrastructure and cities) as impact opportunities. The four cross-cutting factors are human rights, a low-carbon economy, circularity, and digitization.

\subsection{Digitalization in the Chemical Industry}

Compared to sustainability, digitalization is still in its infancy in the chemical industry. At present, the primary focus is on technical-related issues, but digital transformation is not about technology; most types of digital technology provide possibilities for efficiency gains and customer intimacy. Still, if people lack the right mindset to change, and the current organizational practices are flawed, then digitalization will simply magnify those flaws and fail [50]. According to Westerman et al. [51], digitalization initiatives align with three critical areas of digital transformation: customer experience, operational processes, and business models. Digitalization can help chemical companies to achieve the next frontier of excellence in key aspects that are determining the future of the industry, and these strategic objectives can be pursued at different stages of the chemical value chain and in combination with each other, especially in business operation and growth areas.

It is still an open question as to how digitalization will change the chemical industry. According to a broad European chemical industry stakeholder survey [52], the key challenges that will determine the outcome and require the special attention of decision-makers in the chemical industry are as follows:

- Missing advanced digital skills;

- A lack of understanding about the advantages of digitalization;

- Uncertain returns from digital investments;

- A lack of methods and processes for digital transformation.

There are three main ways by which digitalization will affect the chemical industry. The first is applying digital-enabled approaches to improve companies' business processes for functional excellence. The second is using digitalization tools to affect demand patterns in end markets, with implications for the industry's value chains. The third is making changes in digital developments that lead to changes in the business models through which companies capture and create value for customers [53]. These changes happen at the chemical manufacturing plant level, mainly in three dimensions [54]: 
- Data management: Most data lakes will be built on the premises and not be cloudbased, given limited gains from data sharing between sites due to the risk of data security, a lack of speed, and the limited comparability of sites.

- Asset optimization: Yield, energy, and throughput with in-line quality control and predictive-asset reliability will be critical levers.

- People's tasks: Operator workload can be reduced by robotics and automation; the tasks of control room operators will move from "control" to "improve," creating an enormous challenge of upskilling.

\subsection{Lean Enterprise}

Lean manufacturing is a continuous improvement methodology that focuses on minimizing waste within manufacturing systems while maximizing customer value. A lean enterprise (LE) is a group of individuals, functions, and legally separate but operationally synchronized firms with a collective focus on a value stream so they can provide the most value to customers [10]. Womack [55] considers purpose, process, and people as the keys to implementing a lean management system and the essential metrics for evaluating lean efforts. In his opinion, the best lean tool may simply be a pair of good shoes, which allows a manager to walk through the value streams to conduct a detailed investigation. In other words, managers and executives must be capable of thinking "horizontally" across business functions to understand and improve value flows.

The LE starts by aligning the purpose, vision, goals, and strategies communicated throughout the organization with critical measures, targets, and activities. The next focus is on the process for value stream management to ensure the capability of achieving goals to meet customer expectations for product quality, delivery, and cost by utilizing the supply chain at its optimal level. Then, the focus on people ensures evident accountability at all levels, which includes creating skill development programs, resource management systems, human resources, and health and safety programs. Firms must improve these three Ps (purpose, process, and people) continuously so they can move toward a future sustainable lean business [56].

The LE enables optimization over the entire enterprise and coordination with other stakeholders of the value stream to achieve operational excellence in all business functions (not just the manufacturing part). The LE can integrate sales, R\&D, production, service, administration, and even leadership to maximize value creation. The LE must also make sure that its development is in line with the economic, environmental, and social objectives of the enterprise [57]. The general structure of the LE, which contains lean product development, production, and sales and service systems; leadership and culture; and administrative processes, is especially crucial to successful implementation [11]. The LE structure also represents an application of the concepts of lean and sustainability; Taucean [58] addresses the similarities and complementarities of lean and sustainability principles with the purpose of integrating the benefits of the two concepts' tools when used together for industry application. Schreiber et al. [59] propose combining lean principles with selected digitalization tools to develop a lean digital capability for building a sustainable competitive advantage.

\section{Research Methodology}

The research methodology adopted in this study was TOGAF (Section 3.1). With EA determined by enterprise vision, strategic goals, business requirements, and technology [60], TOGAF provides a structural mechanism to depict that architecture, and its actual development/management is achieved with the ADM. Especially, the ADM can effectively manage an EA's lifecycle. There are eight major phases with this architecture method: vision (phase A), business architecture (phase B), information systems architecture (phase C), technology architecture (phase D), opportunities and solutions (phase E), migration planning (phase F), implementation governance (phase G), and architecture change management (phase $\mathrm{H}$ ). Situated in the center of these phases is a rigorous practice 
for managing business requirements (requirements management). Commercial software has been developed to implement the TOGAF ADM, such as the software package offered by Visual Paradigm [61].

The main guideline for LE architecture development is to focus on what values are created for stakeholders and how to develop the selected horizontal/vertical scope and architecture domains. Therefore, three dimensions are typically used to develop the architecture framework of an LE [31]: (1) Breadth: What is the full extent of the LE, and what part of that extent will this architecting effort deal with? The LE extends beyond traditional enterprise boundaries to embrace a combination of business scope with suppliers, customers, government, community, and shareholders. (2) Depth: What level of detail should the architecting effort go into? How much architecture is "enough"? How do we align the LE purpose with processes and people? The architecture framework of an LE is divided into the following parts: company mission, business driver, strategy for operational excellence, business goals, and architecture landscape. (3) Architecture domains and principles: A complete EA should contain the principles for how to develop these architectural domains (business, application, data, and technology) as an LE.

TOGAF is a generic method for architecture development that can deal with the above-mentioned LE requirements. Using TOGAF, we performed an in-depth study of a real business transformation occurring at a major international chemical corporation, extracting the architecture framework possibly adopted by this firm to become an LE. It started with a preliminary phase to establish LE architecture principles and identify the organizations impacted by the LE business transformation. Second was the vision phase, to create the mission, business drivers, strategy, and business goals of an LE. Third, three kinds of architecture were developed in sequence for the LE: business architecture for focused business domains, information systems architecture for application and data, and technology architecture for digital technologies. Finally, the target LE architectures were established for the subject organization, then a gap analysis was performed to identify major differences between as-is and to-be architectures, and migration planning was initiated to analyze potential costs, benefits, and risks for the implementation roadmap. This case study process using TOGAF also aligns with lean manufacturing principles for continuous improvement culture, digital technologies for process optimization, and goals customized for the chemical industry to achieve UNSDGs.

\section{Case Study}

The TOGAF research methodology described above was used to examine an actual case study aimed at understanding the EA framework or model for chemical firms to transform into lean enterprises, involving a major international chemical corporation. Potential challenges were identified for this company to evolve and become an LE, followed by a series of works conducted to develop architectures targeting the company's business, information systems, and technology aspects. Then, gap analysis was conducted to establish migration plans.

\subsection{Case Company}

The case company is an international chemical corporation. With 23,000 employees and an annual revenue of EUR 10 billion, the company manufactures a wide variety of nutrition products and specialty materials for customers worldwide. Urged by industry megatrends and emerging advanced digital technologies, the company has felt tremendous pressure to undergo major business transformations so it can create economic, environmental, and societal value for stakeholders while also adequately addressing global issues.

Figure 1 is an organizational model developed with Visual Paradigm software to display all organizations that could be involved in the LE transformation. Situated in the center are three business groups (BGs) in the company: nutrition, materials, and innovation center. The nutrition BG will produce nutritional products, specialty foods, and hydrocolloids; the materials BG will manufacture engineering materials, resins and 
functional materials, protective materials, and additive manufacturing materials; and the innovation center BG will develop biomedical, advanced solar, and bio-based products and services. These BGs have short- and long-term responsibilities in primary business functions such as innovation and R\&D, direct sourcing, manufacturing and operations, and marketing and sales.

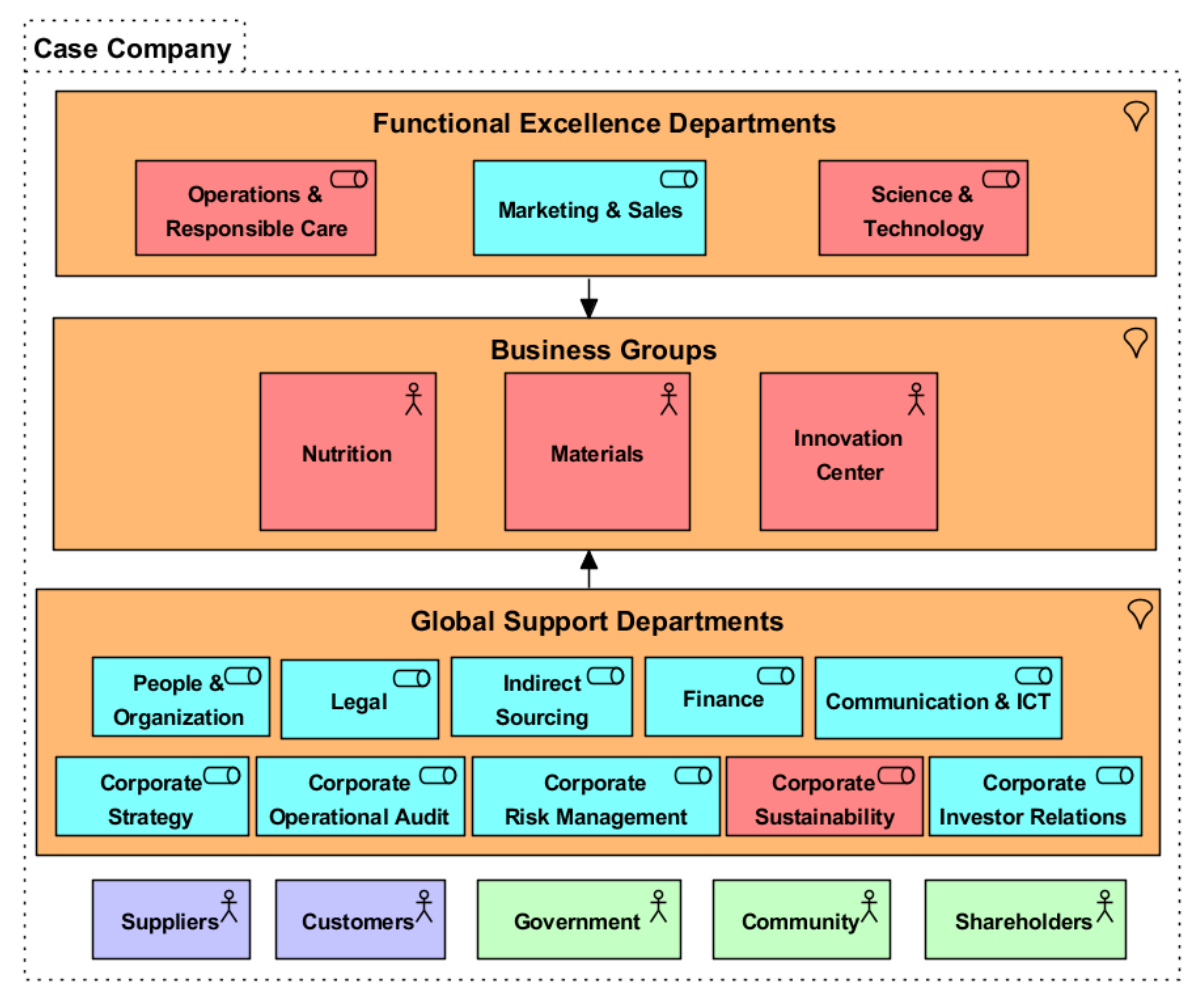

Figure 1. Organizations involved in LE transformation.

The BGs are supported by three functional excellence departments (top of the figure): operations and responsible care, marketing and sales, and science and technology. They assist the BGs to improve corporate performance and establish aspirational targets. The BGs are also supported by a number of global support departments (bottom block in the figure) that provide services in areas such as finance or legal (top row) or execute functions such as corporate operations audit or corporate investor relations (bottom row) to support the managing board/executive committee.

These organizations are given specific colors to indicate the type of impact they will likely experience during the LE transformation: red represents the greatest impact, blue means indirect impact (that is, these organizations may have to adjust the way they work with organizations in red), green represents minor or no impact, and purple represents impacts that already exist (that is, these organizations may already be affected by their own business transformations).

\subsection{Architecture Vision, Principles, and Business Transformation Readiness Assessment \\ 5.2.1. Architecture Vision}

As a high-level aspiration for running the business, the case company has a vision to fully address the needs of people, planet, and profit [8], that is, the triple bottom line (TBL) of sustainability, thereby making substantial contributions for all stakeholders, including customers, shareholders, employees, and society. This architecture vision is firmly based on the following company mission, business driver, key strategy, and business goals:

- Company mission: The company will strive to create sustainable value for all stakeholders by engaging in profitable growth with a scientific approach while also playing an accountable role in the global community. 
- Business driver: Sustainability will drive the business in future markets, enabling the company to develop innovative products/solutions with high margins.

- Key strategy: The strategy is growth and value, which applies to three main business domains: nutrition and health, climate and energy, and resources and circularity. Their development will leverage the company's unique technical capabilities, which will be enhanced further with serious consideration of industry megatrends and the UNSDGs. Moreover, the firm will maintain operational excellence and continue cost control to accelerate profit generation.

- Business goals: The company will strive to achieve a high-single-digit annual increase in adjusted earnings before interest, taxes, depreciation, and amortization (EBITDA), an average $10 \%$ annual increase in adjusted net operating cash flow, a 30\% absolute reduction in GHG emissions by 2030, an average 1\% annual improvement in energy efficiency until 2030, and an increase in purchased renewable electricity to account for $75 \%$ of all power consumption by 2030 . Moreover, the case company will also work hard to raise the employee engagement favorability score to $75 \%$, reduce the safety frequency recordable index to below 0.25 , and accelerate the delivery of sustainable living solutions to more than $65 \%$ by 2021 .

\subsubsection{Architecture Principles}

Architecture principles are a set of principles related to architectural work [62]. They articulate fundamental philosophies or critical thinking for business development, dictating how companies should operate to achieve their strategic objectives. In addition, these principles also play a role in managing architecture processes; that is, they influence EA development and implementation.

Generally, architecture principles are influenced by internal factors, including company mission, strategic initiatives, and current systems; they are also influenced by external factors, such as emerging technology and industry trends. To ensure proper alignment between company vision/key business strategies and target architectures, architecture principles must be clearly articulated to provide precise guidance and full traceability to EA architects.

The architecture principles are specified in the preliminary phase of the TOGAF ADM, consisting of business, data, application, and technology principles for the case company, as follows:

- Business principles: Focus business development on the three business domains; create sustainable value in terms of the TBL for stakeholders; adopt purpose-led and performance-driven growth strategies; and strive to align businesses with UNSDGs.

- Data principles: Integrate enterprise resource planning, customer relationship management, and net promoter score systems to transform customer experience; optimize process data and improve reliability to transform operational performance; pursue innovation in sustainability; and create digital value propositions to create new business models.

- Application principles: Accomplish the company mission by researching/developing innovative and sustainable solutions in main business domains; adopt digitalization to optimize business processes and drive profitable growth; and strengthen $B G$ leadership and company culture to enable continuous improvement.

- Technology principles: Use scientific approaches to extend business reach to as many as 2.5 billion people worldwide.

\subsubsection{Readiness Assessment for Business Transformation}

It is critical to assess firm readiness in order to identify current and potential issues so they can be properly resolved. When doing an LE transformation, the main objective of this assessment is to evaluate the firm's conformity to EA development and identify all potential issues, and tools such as the Canadian Government Business Transformation Enablement Program (BTEP) can be used for this work [63]. The BTEP can assist companies 
in evaluating their readiness to accept changes during phase A (architecture vision) of the TOGAF ADM [31] and implement these changes during phase $\mathrm{F}$ (migration planning) and phase $\mathrm{G}$ (implementation governance). As indicated in the following assessment of the case company, "high" means no readiness issues, "good" means there are relatively minor issues, "acceptable" indicates there are some readiness issues, "fair" indicates some work is needed, and "low" means substantial work is needed before proceeding further in EA development.

The readiness assessment of the case company proceeded as follows. For company "vision," which is concerned with the ability to clearly define and communicate what is to be achieved, the rating was high because the company's impact scope and vision of the target architecture were already clearly defined. "Desire, willingness, and resolution" was assessed as good, because an active dialogue was conducted within the firm to discuss potential impacts associated with the LE transformation and possible resolutions. "Need," which measures whether the firm has a compelling need to execute the endeavor, was also assessed as good because the consequences of failure or success of the endeavor were clearly communicated within the company. With regard to "funding, sponsorship, and leadership, and governance," the case firm is a company limited by shares listed on Euronext Amsterdam and managed by a managing board together with an executive committee and an independent supervisory board. Executives are willing to support corporate governance and risk management-related works. Therefore, this item was assessed as good. There is also "accountability" to measure the assignment of specific and appropriate responsibility. The company had assigned its chief digital officer to be totally responsible for the outcome of EA development projects and their execution. This officer has sufficient expertise and experience to lead digital-related projects, so this factor was rated as acceptable. Finally, for "enterprise capacity to execute" and "enterprise ability to implement and operate," the case company has non-IT resources to do the required work and mitigate the impacts of project implementation, so both were rated as acceptable.

Although the case company received an overall satisfactory result in the above assessment, it has to pay attention to the following three categories due to their unsatisfactory rating:

- The readiness for "workable approach and model execution" was rated as low because there is virtually no industry case or academic research on business transformations in which lean manufacturing, digitalization, and sustainability are all involved. Especially, the lack of best practices in chemical-related industries increases project risks noticeably.

- "Business cases" was assessed as just fair because digitalization is such a new subject for chemical firms that so far, only a few success stories are known to the public. Consequently, the case company is still in the process of collecting related information.

- "IT capacity to execute" was also assessed as fair, as the company is not quite ready to integrate information technology (IT) (e.g., software, computers, and other hardware to perform business operations) with operational technology (OT) (e.g., front-end, field-based devices traditionally associated with manufacturing and industrial environments). That is, there are gaps between IT and OT that hinder the establishment of a common platform that would enable more direct control and complete monitoring of the complex processes.

\subsection{Target Enterprise Architecture}

The target EA provides the future state of EA developed for the case company; the target EA provides the case company with a business-driven plan that describes the desired end state of its business, application, data, and technology architecture. The purpose of the target EA is to effectively plan a course for achieving the strategic vision/goals and provide stakeholders with a view into the complex relationships among these different perspectives. 


\subsubsection{Target Business Architecture}

The target business architecture defines the business strategy, governance, organization, and key business processes. Figure 2 shows the target business architecture for the case company, driven by science-based core competencies, global megatrends, and the UNSDGs to achieve business goals. It depicts how the firm will be operating in the near future. The company has a mission to create sustainable value for all stakeholders, focusing on nutrition and health, climate and energy, and resources and circularity as their main business domains. Therefore, it needs to maintain a proper balance between the need to achieve profitable growth and the need to play a decisive role in the world. There must be substantial efforts to enable and accelerate this business transition. The bottom block of the figure shows that the company will continue its lean practices and maintain cost discipline to reinforce leadership in continuous improvement, optimize business support functions, and develop a global mindset as part of the company culture. It will also adopt the latest digital technologies to enhance customer experience, improve operational performance, and develop new business models to drive growth. More importantly, the company will pursue leadership in sustainability. These strategies should allow the company to achieve more engagement for people, more growth for profit, and more sustainability for the planet, thus fulfilling its commitment to fully address the TBL.

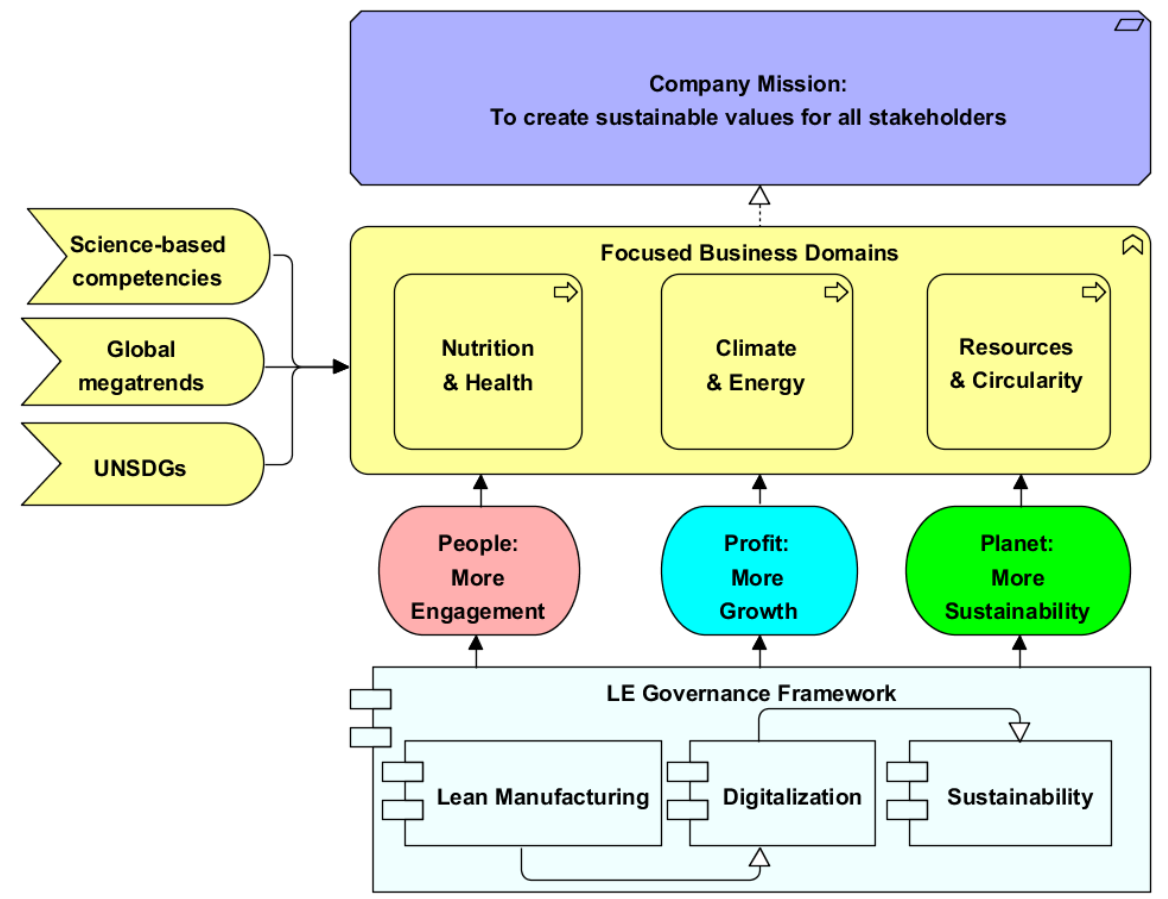

Figure 2. Target business architecture for case company.

\subsubsection{Target Information Systems (Application and Data) Architecture}

The target information systems architecture contains application and data architecture. Figure 3 shows the target application architecture, which in essence is an LE governance framework with three components: lean manufacturing, digitalization, and sustainability, providing an overview of the case company's application landscape. 


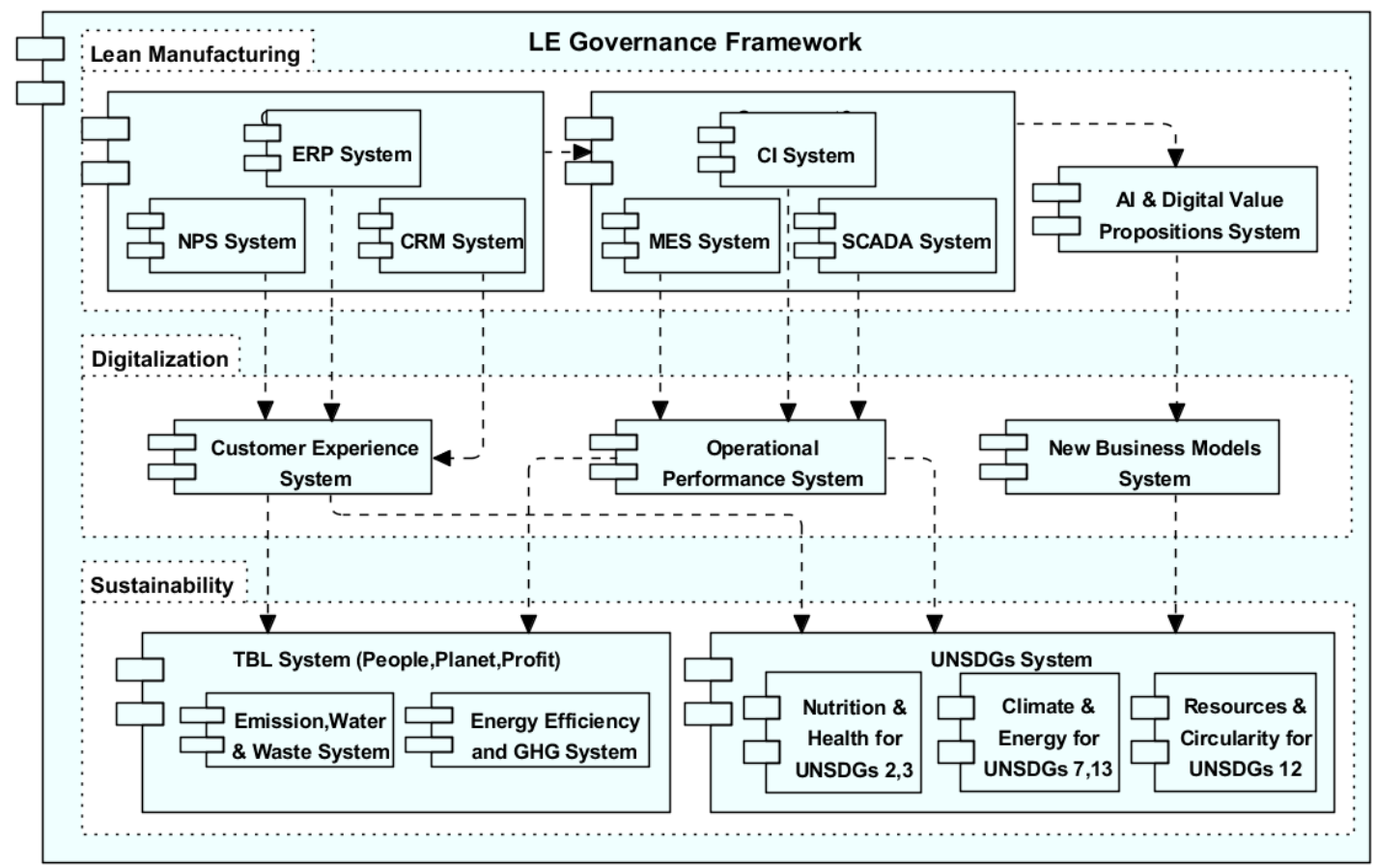

Figure 3. Target application architecture for case company (applicable to all BGs).

In the lean manufacturing component, there is a net promoter score (NPS) system to enhance customer feedback programs, a customer relationship management (CRM) system to handle customer data and complaints, and an enterprise resource planning (ERP) system to integrate business processes such as materials management, production, sales, and distribution in real time. In this component, the manufacturing execution system (MES) will manage work-in-progress and process flows; and there is a supervisory control and data acquisition (SCADA) system to control plant processes by monitoring the overall equipment effectiveness (OEE) and executing total preventive maintenance (TPM) to improve production and quality systems. This SCADA system will connect OEE and TPM with the operational performance system in the digitalization component, which will function as an interface between this component and the TBL and UNSDG systems in the sustainability component. In addition to MES and SCADA, the continuous improvement (CI) system is a digital platform to integrate various improvement efforts, including teamwork, 5S, quality, reduction in setup time, and visual management, to become a cohesive system. Therefore, CI can align daily practices with company strategies to ensure sustainable results. Finally, the AI and digital value proposition system will optimize processes and customize products, executing a high-mix, low-volume form of manufacturing as required by the new business model.

The digitalization component includes a customer experience system, an operational performance system, and a new business model system. For the case company, digitalization is not just about adopting IT and new technology; this component must also have good alignment with the lean manufacturing component. For example, customer experience must be properly aligned with NPS, CRM, and ERP, and operational performance must be properly aligned with CI, MES, and SCADA. All systems in this component are also driven by leadership in the sustainability component, such as TBL and the UNSDGs.

The sustainability component uses a TBL system to monitor GHG emissions, water consumption, waste generation, and energy efficiency; during the monitoring process, improvement targets are set and readjusted when necessary. This component will also provide opportunities for digital businesses and develop new technology in order for each business domain to support specific UNSDGs. To be precise, nutrition and health will support UNSDGs 2 (zero hunger) and 3 (good health and well-being), climate and energy 
will support UNSDGs 7 (affordable and clean energy) and 13 (climate action), and resources and circularity will support UNSDG 12 (responsible consumption and production).

The target data architecture describes the main data objects that the LE governance framework will handle to realize the kind of business depicted in the target business architecture (Figure 2). As seen in Figure 4, the LE governance framework uses specific data objects to execute the desired business functions, such as manufacturing departments of BGs using manufacturing, marketing, and sales data to manage daily operations; functional excellence departments using site performance data (including CI, OEE, and TBL) to realize functional excellence in lean manufacturing and sustainability; and global support departments using corporate functions data (e.g., corporate strategy and operational audit) and support function data (e.g., people and organization, finance, and legal) to strengthen the BGs' corporate governance and risk management. In order to sustain operational excellence, functional excellence and global support departments will conduct independent audits every two years to certify the BGs' compliance with the architecture vision and principles. They will also prepare progress data on risk management and sustainability to allow the BGs to maintain vital communication with stakeholders during the LE transformation. Support function data will be integrated across the enterprise to enhance business function efficiency and capture scale benefits. BG operations data will consolidate R\&D, operations, marketing and sales, and other value chain activities to achieve continuous improvement across all BGs.

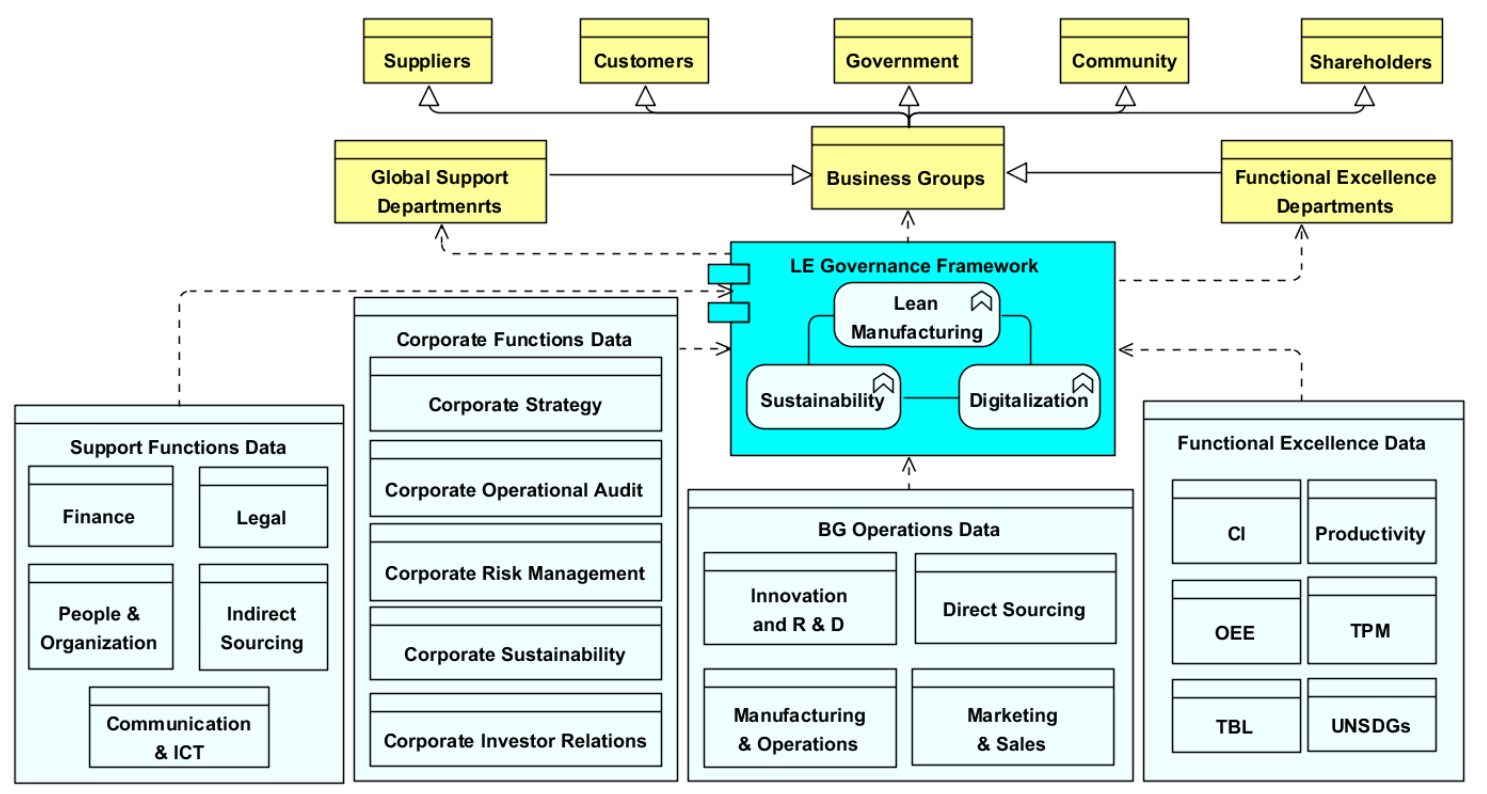

Figure 4. Target data architecture for case company.

\subsubsection{Target Technology Architecture}

The target technology architecture captures technologies essential for the successful execution of LE transformation, containing system software, database, middleware, networks, and other key software or hardware elements to provide the necessary support to the LE governance framework (Figure 3). This target architecture also contains emerging technologies, especially AI and IoT, that the company will likely adopt to capture new opportunities from the LE transformation. Figure 5 shows the target technology architecture for the case company, comprising a wide area network (WAN) (center) integrated with three local area networks (LANs): lean manufacturing, sustainability, and digitalization. Using science-based technologies to closely follow global megatrends and the UNSDGs, this architecture will allow the case company to extend its business reach to 2.5 billion people worldwide and create sustainable value with regard to the TBL. 


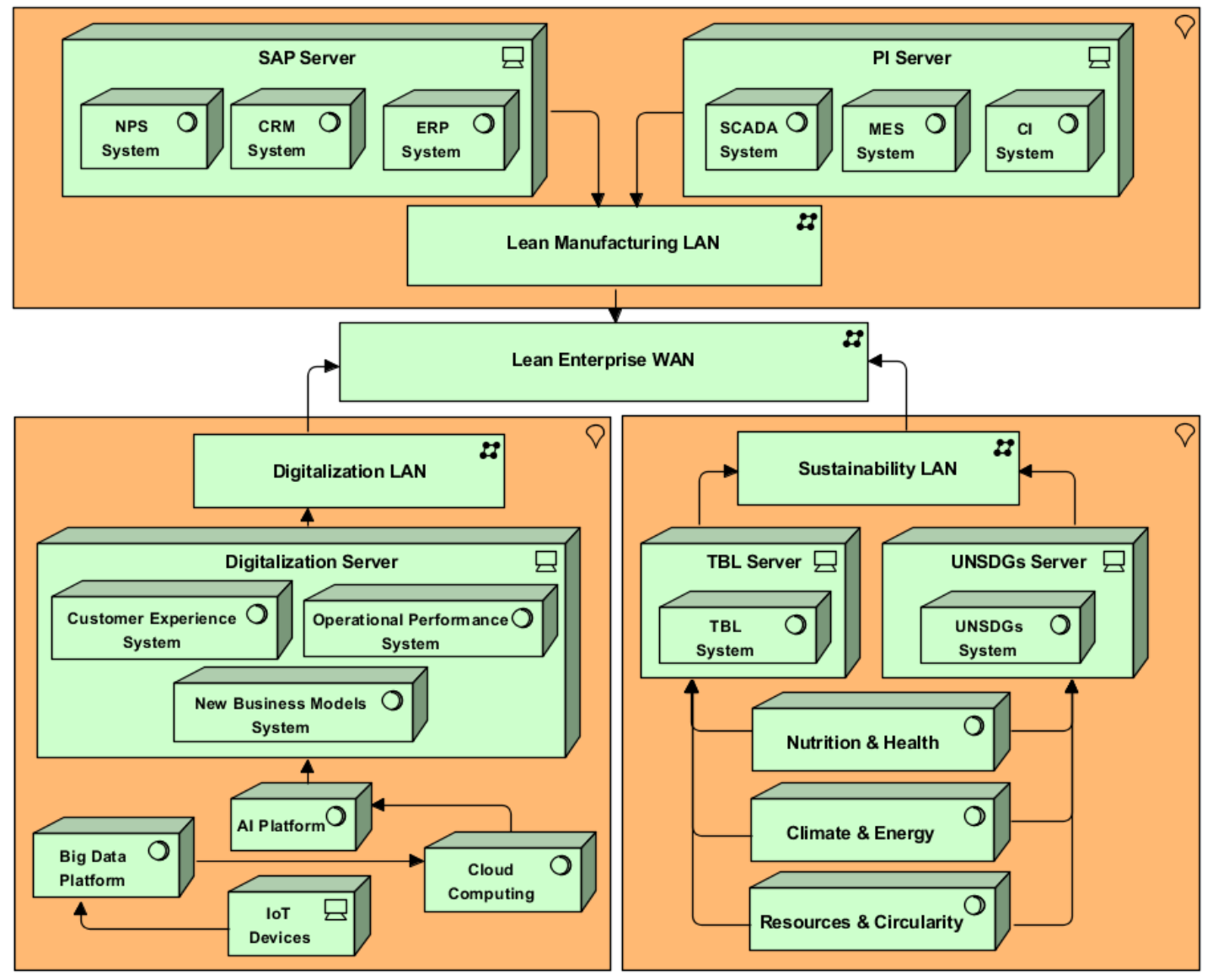

Figure 5. Target technology architecture for case company.

The lean manufacturing LAN contains an SAP and a plant information (PI) server. The SAP server will host NPS, CRM, and ERP systems to support daily routines such as production planning, material management, sales/distribution, and monitoring of customer feedback. The PI server will host systems including SCADA, MES, and CI to perform tasks such as real-time monitoring of OEE and abnormal variation feedback on TPM to facilitate continuous improvement across all BGs. The PI server will also play a significant role in company-wide efforts to reduce production waste, lower GHG emissions, and increase energy efficiency, making direct contributions to sustainable development and the UNSDGs.

The digitalization LAN contains servers to host customer experience, operational performance, and new business model systems. These systems are equipped with a variety of new digital technologies, including IoT devices for automatic data collection, big data platforms and cloud computing for smart data analysis, and AI platforms for the efficient conversion of massive data to create valuable information. Consequently, this digitalization LAN should noticeably increase the efficiency of manufacturing processes and resource utilization, thus allowing the company to better respond to urgent pull-in requests by customers.

The sustainability LAN contains servers to host systems related to the TBL and UNSDGs. The TBL system will run a variety of tasks that fall into the dimension of profit, planet, or people. Tasks in the profit dimension are related to anti-bribery, anti-corruption, and awareness of cyberfraud; tasks in the planet dimension are Responsible Care initiatives aimed at GHG emissions, energy efficiency, and renewable energy; and tasks in the people dimension are related to implementing life-saving rules, preventing unlawful harassment, and conforming with data privacy. The UNSDG system will be used to process data for UNSDG-related tasks, including collaborating with the UN to develop new food solutions 
(UNSDG 2, zero hunger), produce biomedical devices to improve the quality of life for surgical patients (UNSDG 3, good health and well-being), develop advanced solar and biofuel technologies for better renewable efficiency (UNSDG 7, affordable and clean energy), produce key materials to enable a circular economy or lower VOC emissions (UNSDG 12, responsible consumption and production), and develop animal feed solutions to improve resource efficiency and reduce GHG emissions (UNSDG 13, climate action).

\subsection{Gap Analysis}

Table 2 lists all the major gaps between the existing (baseline) and target architectures. They represent problems or potential issues in the business where improvements are required so the company can finish the LE transformation successfully. These gaps also provide crucial information for determining migration plans (Section 5.5).

Table 2. Gap analysis of case company.

\begin{tabular}{lcc}
\hline \multicolumn{1}{c}{ Gaps } & Related Architecture & Priority \\
\hline 1. Insufficient understanding of cybersecurity issues & Data, technology & Medium \\
\hline 2. Slow action to reduce environmental impact & Business, application & High \\
\hline 3. Slow response to climate issues & Business, technology & High \\
\hline $\begin{array}{l}\text { 4. Insufficient digital talent } \\
\begin{array}{l}\text { 5. Insufficient customer-centricity and cost-consciousness } \\
\text { (for organizations to pursue growth targets) }\end{array}\end{array}$ & Business, technology & Medium \\
\hline $\begin{array}{l}\text { 6. Virtually no business transformation cases in chemical } \\
\text { industry involving lean manufacturing, digitalization, and } \\
\text { sustainability together }\end{array}$ & Technology & Medium \\
\hline 7. Insufficient understanding of TBL dynamics & Data, application & High \\
\hline
\end{tabular}

For the three BGs, the analysis indicates that one of the major challenges will probably come from climate-related issues, especially capturing the carbon footprint across the vast value chain in order to accurately measure overall GHG emissions. An even bigger challenge is digitalization. Although the company realizes this is a megatrend for the chemical industry, it does not have sufficient talent to perform all of the required tasks. In addition, the top management does not seem to truly understand the kind of impact that digital technologies could potentially have, thus adequate leadership must be provided to create a sense of urgency around those necessary changes. Moreover, there are also issues with the information systems, including cybersecurity and how these systems should function to support the implementation of customer-centric business models. Finally, there are virtually no cases reported in the chemical industry where lean manufacturing, digitalization, and sustainability are all involved in transforming a business. The dynamics of how one philosophy can affect another is unclear, and this lack of understanding means that the case company could be exploring untested waters with no previous success stories to follow.

The case company will require various skill sets to achieve the desired LE transformation. That is, it will continue to rely on current skill sets to maintain operational excellence for lean manufacturing but will definitely require new skill sets to handle digitalization and sustainability-related tasks. In general, lean manufacturing uses traditional methods such as continuous improvement and Six Sigma to maintain operational excellence. Digitalization, however, requires the capability to offer digital solutions or services so the business can keep up with changing customer preferences, and sustainability requires the capability to create innovative but sustainable solutions in time. This suggests that different leadership, company culture, and operation practices will be required for the new business domains. How to introduce them into the current environment will surely be a challenge for top management. 


\subsection{Migration Plans}

Following the above gap analysis, a number of appropriate migration plans can be determined to ensure the full realization of target architectures (Table 3). With consideration of readiness assessment, these plans provide another opportunity for key stakeholders to better understand new business values.

Table 3. Migration plans for case company.

\begin{tabular}{ll}
\hline \multicolumn{1}{c}{ Gaps } & \multicolumn{1}{c}{ Migration Actions } \\
\hline 1. Insufficient understanding of cybersecurity issues & $\begin{array}{l}\text { Conduct risk assessment for IT, OT, and R\&D systems; } \\
\text { initiate awareness campaigns; implement } \\
\text { cybersecurity programs }\end{array}$ \\
\hline 2. Slow action to reduce environmental impact & $\begin{array}{l}\text { Advocate transition from linear to circular and bio-based } \\
\text { economy; execute responsible care plans to reduce waste } \\
\text { and GHG emissions }\end{array}$ \\
\hline $\begin{array}{l}\text { 3. Slow response to climate issues } \\
\text { 4. Insufficient digital talent }\end{array}$ & $\begin{array}{l}\text { Review and revise sustainability targets with proper } \\
\text { frequencies, especially those related to GHG emissions, } \\
\text { energy efficiency, and renewable energy usage }\end{array}$ \\
\hline $\begin{array}{l}\text { 5. Insufficient customer-centricity and } \\
\text { cost-consciousness (for organizations to pursue } \\
\text { growth targets) }\end{array}$ & $\begin{array}{l}\text { Appoint chief digital officer to oversee strategies and } \\
\text { talent policies for digital transformation }\end{array}$ \\
\hline $\begin{array}{l}\text { 6. Virtually no business transformation cases in } \\
\text { chemical industry involving lean manufacturing, } \\
\text { digitalization, and sustainability together }\end{array}$ & $\begin{array}{l}\text { Execute customer-centric programs and upgrade sales } \\
\text { forces to help organization become more agile; initiate } \\
\text { value-creating acquisitions to evolve cost competence }\end{array}$ \\
\hline $\begin{array}{l}\text { Assign operations and responsible care department to be } \\
\text { in charge of surveying industries to locate success stories } \\
\text { or useful information on digitalization or sustainability }\end{array}$ & Medium \\
\hline 7. Insufficient understanding of TBL dynamics & $\begin{array}{l}\text { Align business goals with UNSDG 2 (zero hunger), 3 } \\
\text { (good health and well-being), 7 (affordable and clean } \\
\text { energy), 12 (responsible production and consumption), } \\
\text { and 13 (climate action) and set individual targets to } \\
\text { be accomplished }\end{array}$ \\
\hline
\end{tabular}

The case company can choose four types of work packages for its migration plans. These are business or technology-related works or projects aimed at filling the gaps in the realization of target architectures. For gaps 2 and 3, the company can use "scope" work packages to establish directions for growth and adjust product portfolios. To follow the transition from a linear to a circular and bio-based economy, the case company can increase its usage of bio-based ingredients, adopt waterborne coatings (to replace traditionally used solvent-based coatings), and use 3D printing in prototyping (to reduce waste production) in its resources and circularity business domain. Measures in the climate and energy business domain to reduce carbon footprints will allow the company to accelerate climate actions and become a low-carbon enterprise in time. Next, for gap 5, it can execute "organic growth" work packages to enhance customer-centricity. Most certainly, these work packages would be performed on the NPS, a system that runs on the SAP server to measure customer satisfaction/loyalty and communicate with functional areas in the case company such as finance, innovation, and procurement. In addition, measures to increase digital competencies among commercial employees can further enhance the customer experience. Last but not least, by leveraging unique company technologies with solution-oriented strategies, the case company can offer innovative and sustainable products/services. All of these are significant approaches for the case company to achieve the desired customer-centricity targets. In addition to organic growth, the company can also adopt "inorganic growth" work packages to fix gap 5. These work packages contain strategies and procedures for value-creating mergers and acquisitions, which has been the company's main approach to maintain leadership in the nutrition and health markets. 
Finally, to remove the remaining four gaps (gaps 1, 4, 6, and 7), the company can adopt "enabling programs" work packages to perform a series of works on lean manufacturing, digitalization, and sustainability. The aim of lean-related works is to achieve integrated and continuous improvement across all BGs. Digitalization-related works may include adopting omni-channel apps to enhance customer experience, using digital IT/OT collaboration tools to improve operational performance, and developing new business models (based on digital value propositions) to offer personalized nutrition and animal feed. Sustainabilityrelated works may include using recycled materials to produce engineering plastics, using solid waste materials (e.g., solid recovered fuels) to produce energy, capturing wastewater methane gas to lower GHG emissions (while also producing renewable electricity), and so on. To measure the full economic, environmental, and societal impacts of various product lines, the case company has made life cycle analysis an integral part of its business processes, which will certainly help it to align its business goals with the UNSDGs. In terms of responsibility, it would be appropriate to let the operations and responsible care department administer the lean manufacturing and sustainability projects and appoint a chief digital officer to oversee digitalization projects.

\section{Research Contributions}

\subsection{Lean Enterprise Architecture Framework for the Chemical Industry}

By using TOGAF to complete the case study, as described in the previous section, we obtained a lean enterprise architecture framework (LEAF) to seamlessly integrate lean manufacturing, digitalization, and sustainability for firms in the chemical industry (Figure 6). LEAF is a holistic architecture framework depicting the essence of a successful business in the new era of circular economy. Using this framework, firms can build a culture of continuous improvement with lean manufacturing, enhance process improvement with digital technologies, and pursue UNSDGs for sustainable development. The TOGAF ADM allows this framework to be created in a smooth manner. As a start, the architecture vision is firmly based on the company mission as well as business strategies and goals, depicting a grand future in which the company will strive to pursue sustainable values covering the TBL. Next, the architecture principles are outlined to guide the creation of various target architectures, including the business architecture, which focuses on growth in nutrition and health, climate and energy, and resources and circularity; the IT architecture, which is an LE governance framework with main data objects to realize the business architecture; and the technology architecture, which comprises an LE WAN integrated with various types of LANs. The resulting LEAF can be a brief roadmap and corporate governance architecture, which means delivering value such as effective communication and an analytical framework for firms to complete the necessary transformations for the future.

The LEAF is an economic model in which companies must envision a sustainable type of future and extend their business goals from simply chasing the highest profits to also caring about the well-being of fellow citizens, society, and the environment. That means they have to renovate product/service portfolios and adjust organizational structures accordingly. In this regard, the LEAF is the first model of its kind to reveal a clear path for the chemical industry. It covers visions for future business, corresponding growth strategies, and how companies may want to change or improve their organizational and other business infrastructures. Especially, the LEAF develops the LE governance framework for IT architecture and digitalization LAN. Thus, it leverages digitalization in three key areas to link lean manufacturing and sustainability: operational performance (lean manufacturing: people), customer experience (digitalization: process), and new business models (sustainability: purpose). Furthermore, the LEAF supports the chemical industry in aligning sustainability drivers with LE WAN digital technologies. The lean manufacturing LAN contains an SAP server with NPS, CRM, and ERP systems to support daily routines and a PI server with SCADA and MES for manufacturing management. The LE WAN also incorporates the sustainability LAN with TBL and UNSDG systems to achieve TBL 
business goals and UNSDG targets. Therefore, the LEAF is linked to the architecture vision with a strategic roadmap and consensus building, following a value-driven purpose of sustainability to develop the target EA for LEs in the chemical industry. This holistic framework and development process helps to accelerate the transformation to reach sustainability goals, strengthen operational performance, and leverage digitalization to create value for customers and value-stream stakeholders. Thus, the LEAF can embed sustainability even more deeply into business goals with measurable targets.

\section{Lean Enterprise Architecture Framework}

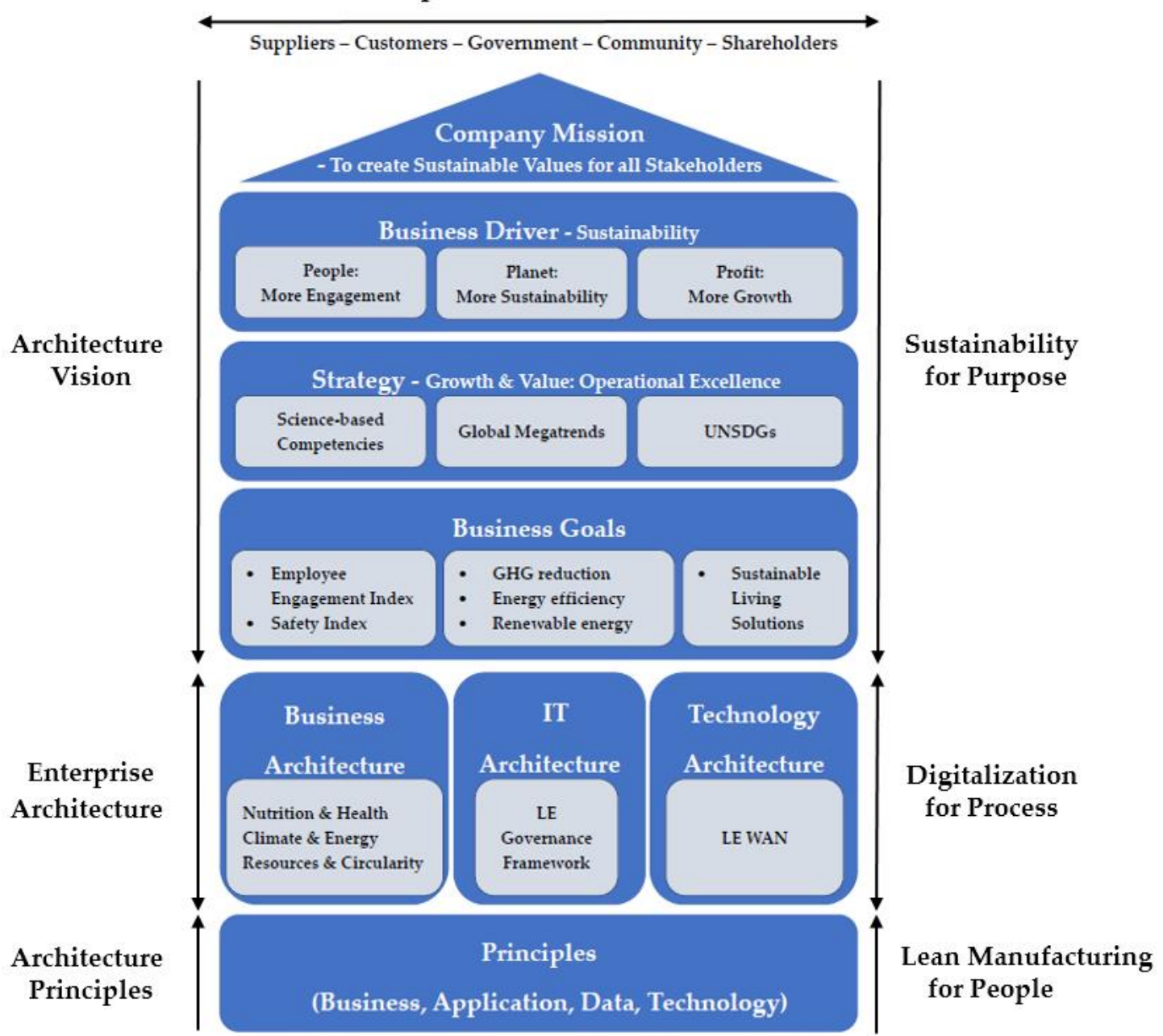

Figure 6. LEAF for chemical industry.

In contrast to traditional EA development processes, which are often complex, timeconsuming, and inflexible, the LEAF is a visualized, customized, and capability-based framework developed for emerging chemical markets. Using the LEAF as a systematic, comprehensive framework, chemical firms can understand what to expect, how to manage change, and how to engage the entire organization in the change process by aligning the company's purpose, process, and people. Another problem with traditional approaches is that they are based on a linear, process-oriented type of thinking. That is, the desire to improve the past (i.e., existing problems) dominates EA development, in a so-called as-is change of mindset. Such approaches have a major drawback, in that the past inevitably sets certain boundaries that constrain many possibilities. In contrast, the LEAF is developed from a to-be type of mindset that believes future business visions direct EA development. Integrated with current megatrends in the chemical industry, the LEAF can enable firms to capture business opportunities in emerging markets, including renewable energy (due 
to global warming) and various product life cycle solutions (as demanded by the circular economy). The early involvement of top management is also a major feature of the LEAF, which is absolutely necessary because LE transformation is a strategic issue rather than an IT or another lean project. Therefore, the full engagement of top management is a must to ensure successful completion.

Applying the LEAF to other chemical companies developing target EAs could proceed as follows. Starting in stage one, the company should identify the impacted organizational scope and stakeholder concerns, and fully commit to defining the development principles for business, IT, and technology architectures. The architecture vision will lead the company to set up its mission for sustainability purposes, which is fully anchored in the business driver for the TBL and business strategy on the focused business domains. Then, stage two is to develop the right architectures to implement business goals. The business architecture focuses on improving operational performance in the business domains, the IT architecture focuses on enabling customer experience by the LE governance framework, and the technology architecture focuses on advocating sustainable business models by LE WAN. Next, stage three is to get the architectures ready; that is, to find opportunities and solutions for gaps when developing the target EA, which is linked to work packages for migration plans to fill the gaps in realizing the target architectures. Finally, stage four is to get the architectures up and running. Applying architectural governance for successful management consolidates the various implementation work packages, while managing change to ensure the architectures are working to achieve the original company mission and architecture principles.

In summary, because the public's view of the chemical industry is that it consumes many materials and energy resources, it has been accused of overexploiting natural resources and causing air, water, and land pollution. The LEAF can assist the chemical industry in achieving the UNSDGs to achieve a better and more sustainable future for all. The LEAF proposes the target EA that aligns the TOGAF ADM phases with the LE transformation by integrating lean manufacturing, digitalization, and sustainability. The lean manufacturing principles for continuous improvement and people-oriented culture will guide the architecture principles to develop the target architectures of business, IT, and technology. The gap between as-is and to-be architecture will impact the organization and value stream. Thus, the firm has to implement migration plans during the LE transformation, which should consider the business drivers and aim to achieve the TBL as follows: (1) more sustainability, by reducing risk exposure and costs by working with value chains to reduce emissions and deal responsibly with energy and other resources; (2) more growth, by identifying consumer needs and responding with differentiated, science-based innovations to make a collaborative contribution to the UNSDGs with customers; and (3) more engagement, by building employee motivation, connecting with ESG committed investors, and advocating for the future of the industry and society.

\subsection{Lean Enterprise Model for the Chemical Industry}

Based on the comprehensive case study examination, Figure 7 depicts another major contribution of this research: a lean enterprise (LE) business model containing critical elements and their dynamics, which could function as a transformation blueprint for ordinary chemical firms. This model contains three major elements: lean manufacturing, digitalization, and sustainability. Lean manufacturing strives to maximize customer value and minimize resource waste to maintain operational excellence. Successful digitalization improves firm performance and customer experience while enabling sustainable business models by capturing complete data and information along the value chain. The world's leading companies are doing well by doing good to integrate sustainability into their business strategy and daily practices. Elkington [64] states that companies should adopt the TBL instead of focusing purely on their financial profit targets. Then they can also transform their businesses to be good for the planet and people. Furthermore, the LE model is a business framework in which LE exists at an intersection with TBL to combine 
social, environmental, and economic aspects. The most challenging part for any company is to realize the interaction and dynamic influence between the three dimensions of lean manufacturing, digitalization, and sustainability. The chemical industry's real application practices are defined and evaluated as follows to emphasize the importance of taking into account the mutual relationships of the three intersection areas.

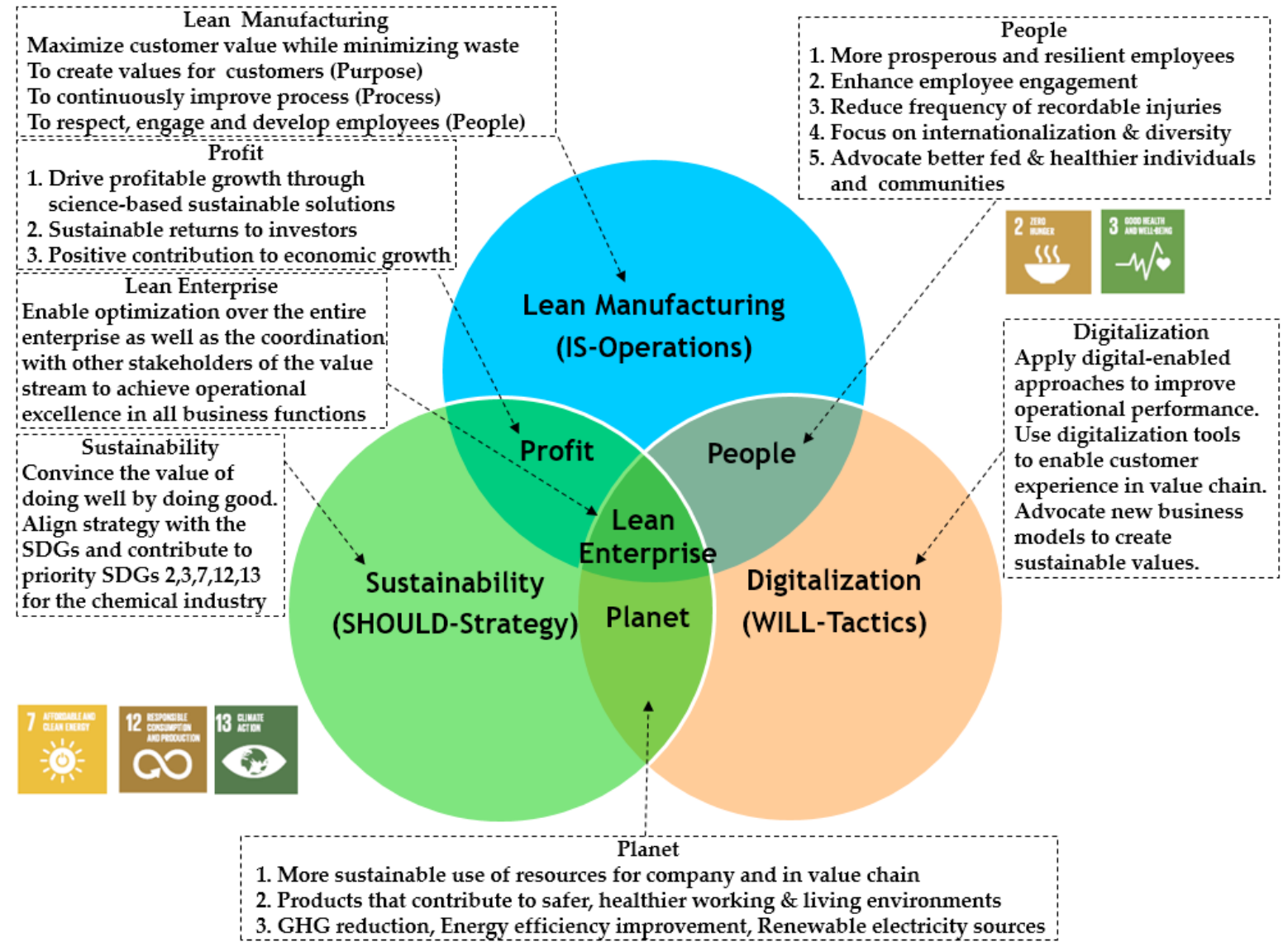

Figure 7. LE model for chemical industry.

6.2.1. Lean Manufacturing and Digitalization for People (Social Aspect): More Engagement by Employees and Societies

Lean manufacturing is people-oriented in terms of respecting, engaging, and developing employees, driven by a customer focus and oriented toward continuous improvement. The essential elements of lean manufacturing start from defining the purpose of values to create and the problems to solve. Then, process improvement is initiated by value stream management. Finally, people are engaged to enable the process and purpose. The idea of people as the key element of lean manufacturing includes their capability, leadership behavior, lean thinking, and culture. Digitalization in the chemical industry mainly happens in three dimensions: data management, asset optimization, and, most importantly, dramatic changes to people's tasks in the plant. Digitalization will transform the customer experience, operational performance, and business models; these actions are all related to people. Therefore, people (social) represent the intersection of lean manufacturing and digitalization. Putting people first, the convergence of lean manufacturing and digitalization technology will achieve the purposes of making improvements for people: having easier, better, and faster processes. Thus, lean manufacturing and digitalization only work when they pair technology with the right people skills and drive change from people's thinking and mindset and the organizational culture. Satisfied employees will provide better customer service and contribute more to society for UNSDGs 2 (zero hunger) and 3 (good health and well-being). 
6.2.2. Digitalization and Sustainability for the Planet (Environmental Aspect): Achieving More Sustainability by Lowering Costs and Risks

The essence of sustainability is to engage in the kind of development that meets the needs of the present without compromising the ability of future generations to meet their own needs [41]. As a result, sustainability and the circular economy have become important areas in which to initiate digitalization campaigns (e.g., adopt new digital operation models for sustainability, simulate the performance of clean technologies, and predict the carbon footprints of new products) [13]. Chemical firms must align digitalization strategies with environmentally related UNSDGs, such as 7 (affordable and clean energy), 12 (responsible consumption and production), and 13 (climate action). Advanced digital technologies, including $\mathrm{AI}$, IoT, and big data analysis, are useful tools for reducing waste, increasing energy efficiency, lowering GHG emissions, and mitigating product carbon footprints. With simulations to determine risk-free outcomes and estimate minimum resource requirements, digital-twin is another promising solution for reducing environmental impacts. This could enable a more sustainable way to utilize resources, thus creating a lower cost/risk situation for chemical firms. Therefore, the planet (environment) will benefit from the use of digital technologies for sustainable development.

6.2.3. Lean Manufacturing and Sustainability for Profit (Economic Aspect): More Growth with Sustainable Solutions

Lean manufacturing strives to develop performance-driven organizations to enable continuous improvement. Under this philosophy, minimizing waste is the main approach to maintaining cost discipline. Another challenge is to develop customer-centric organizations aligned with market/customer segments to create value for customers. At present, chemical companies are feeling tremendous pressure from their customers and communities to improve their ESG practices. As a proper response, they also need strategies to meet corporate social responsibilities. Many firms have accepted that sustainability is a critical business driver for the future; in the case company, two of its three business domains (climate and energy, and resources and circularity) are related to sustainability to a certain degree. Notably, following the spirit of lean manufacturing can enhance business growth with sustainability, such as continuously improved savings in energy, water, and other resources. The same spirit can also contribute to the development of more sustainable product portfolios or business models. This implies that lean manufacturing can enhance the effect of sustainability and make more profit (economic outcome) for the firm.

\subsubsection{Lean Manufacturing-Digitalization-Sustainability: LE to Balance TBL}

As elaborated above, an LE utilizes lean manufacturing to achieve operational excellence, digitalization to enhance customer experience, and sustainability to cultivate new business models. The LE model (Figure 7) implies a business vision of doing well by doing good for sustainability and doing more with less for lean manufacturing. Advanced digital technologies can augment firm performance in creating sustainable value and reducing production waste. The proper alignment of economic, environmental, and social goals allows LEs to enhance the performance of the entire value stream and address stakeholder concerns. The aim is to fully integrate, coordinate, and optimize the whole system by avoiding local improvements within individual business segments that might negatively influence neighboring business areas. The chemical industry can adopt the model to transform into an LE to create value in the three dimensions of people, planet, and profit for all stakeholders.

\section{Conclusions}

The chemical industry manufactures an astonishing variety of products, but also consumes massive amounts of materials and energy. Firms in this industry are currently under tremendous pressure to transform their organizations toward becoming lean enterprises, with the capability of following the traditional lean manufacturing philosophy with new 
competing digitalization challenges and sustainability strategies. Thus, chemical firms can address economic, social, and environmental performance to remain competitive and create value for all stakeholders. Using TOGAF, we performed an in-depth study on a real business transformation occurring at a major international chemical corporation, extracting the architecture framework possibly adopted by this firm to become a lean enterprise and aiming to understand the enterprise architecture framework or model for chemical firms to transform into LEs. The case company's target business architecture follows a growth and value strategy to balance the need to achieve profitable growth with the need to play a decisive role in the world. The target architecture includes three primary data objectives: global support, BG operational, and functional excellence data. The target application architecture applies the LE governance framework of lean manufacturing, digitalization, and sustainability to create an overview of the organization's application landscape. Finally, the target technology architecture comprises an LE WAN integrated with three LANs of lean manufacturing, sustainability, and digitalization to extend business reach to 2.5 billion people worldwide in three business domains: nutrition and health, focusing on UNSDGs 2 (zero hunger) and 3 (good health and well-being); climate and energy, focusing on UNSDGs 7 (affordable and clean energy) and 13 (climate action); and resources and circularity, focusing on UNSDG 12 (responsible consumption and production).

This study proposes the LEAF as a concrete solution for developing LE architecture and providing a brief roadmap for the chemical industry, which means delivering value such as effective communication and an analytical framework for firms to use to create a vision for the future business and corresponding growth strategies, and how to change or improve their organizational and other business infrastructures. Especially, the LEAF develops the LE governance framework for IT architecture and digitalization LAN. Thus, it leverages digitalization in three key areas to link lean manufacturing and sustainability: operational performance (lean manufacturing - people), customer experience (digitalizationprocess), and new business models (sustainability-purpose). Furthermore, the LEAF supports the chemical industry in aligning sustainability business drivers with LE WAN digital technology. This holistic framework and development process helps accelerate the transformation to reach sustainable industry goals, strengthen operational performance, and leverage digitalization to create value for customers and value-stream stakeholders. The LEAF can embed sustainability even more deeply into business goals with measurable targets. This study also contributes to developing an LE dynamics model with digitalization and sustainability for the future chemical industry. This LE model explores the three intersection areas: (1) lean manufacturing-digitalization: more engagement by employees, shareholders, and society for people (social aspect); (2) digitalization-sustainability: more sustainability by lowering costs and risks to the planet (environmental aspect): and (3) lean manufacturing-sustainability: more growth by innovative sustainable solutions for profit (economic aspect). The LE represents the three intersection areas of the TBL to balance social and environmental responsibility and economic value.

The LEAF can be implemented as a practical EA visualization tool for LE transformation. Moreover, it provides a stakeholder-centric view of the enterprise that integrates the organization's capabilities around lean manufacturing, digitalization, and sustainability, as compared to function- or process-based approaches. However, this study's limitation is that it has not been sufficiently tested by other firms, because our proposed LEAF and LE model come from a specific industry case, so their application to other firms would require certain customization or adaptation, because the LEAF cannot provide a transformation scope, company mission, and business goals; these have to be determined by the organization itself. Therefore, in future research, the authors intend to conduct a comprehensive analysis of the LE transformation by applying the LEAF to different chemical firms, and to use different EA methodologies like the Zachman framework to study the interactions between lean, digitalization, and sustainability for different industries. The purpose is to initiate a workable EA to reduce the complexity and risk during LE transformation. 
Author Contributions: Conceptualization, M.-H.L. and C.-T.W.; methodology, M.-H.L.; software, M.-H.L.; validation, M.-H.L. and C.-T.W.; formal analysis, M.-H.L.; investigation, M.-H.L.; resources, M.-H.L.; data curation, M.-H.L.; writing—original draft preparation, M.-H.L.; writing-review and editing, C.-T.W.; visualization, M.-H.L.; supervision, C.-T.W.; project administration, M.-H.L. and C.-T.W.; All authors have read and agreed to the published version of the manuscript.

Funding: This research received no external funding.

Institutional Review Board Statement: Not applicable.

Informed Consent Statement: Not applicable.

Conflicts of Interest: The authors declare no conflict of interest.

\section{References}

1. Thienen, S.V.; Clinton, A.; Mahto, M.; Sniderman, B. Industry 4.0 and the Chemicals Industry: Catalyzing Transformation through Operations Improvement and Business Growth; Deloitte University Press: New York, NY, USA, 2016.

2. Oxford Economics. The Global Chemical Industry: Catalyzing Growth and Addressing Our World's Sustainability Challenges; International Council of Chemical Associations (ICCA): Washington, DC, USA, 2019.

3. Peleman, S. A holistic framework and development agenda for accelerated transition towards a sustainable chemical industry. J. Bus. Chem. 2019, 3, 165-179.

4. Vollmer, M. The road ahead: Digitalization fuels innovation. J. Bus. Chem. 2018, 15, 24-26.

5. Market Research. 3 Megatrends in the Chemical Industry. Available online: https://blog.marketresearch.com/3-megatrends-inthe-chemical-industry (accessed on 28 February 2020).

6. Meincke, H.; Nickel, J.P.; Westerheide, P. Chemistry 4.0-Growth through innovation in a transforming world. J. Bus. Chem. 2018, 2, 42-53.

7. Meincke, H.; Nickel, J.P.; Falter, W.; Keller, A. Chemistry 4.0 Growth through Innovation in a Transforming World; German Chemical Industry Association (VCI): Frankfurt, Germany, 2017.

8. DSM. 2018 Integrated Annual Report. Available online: https://annualreport.dsm.com/ar2018/en_US/index.html (accessed on 4 March 2020).

9. Flaherty, J.E. Peter Drucker: Shaping the Managerial Mind; Jossey-Bass In: San Francisco, CA, USA, 1999.

10. Womack, J.P.; Jones, D.T. From Lean Production to the Lean Enterprise. Harv. Bus. Rev. 1994, 3, $93-103$.

11. Dombrowski, U.; Wullbrandt, J.; Fochler, S. Center of Excellence for Lean Enterprise 4.0. Procedia Manuf. 2019, 31, 66-71. [CrossRef]

12. United Nations Sustainable Development Goals (UNSDGs) Knowledge Platform. Available online: https: / / sustainabledevelopment. un.org/?menu=1300 (accessed on 3 March 2020).

13. Yankovitz, D.; Dickson, D.; Hussain, A. Achieving the Next Frontier of Chemicals Excellence—Digital Maturity Model to Help Ease the Transition; Deloitte Touche Tohmatsu Limited: London, UK, 2019.

14. Bartels, R.; Bjacek, P.; Sarathy, V.; Elser, B. Catalyzing the New-Driving Chemical Industry Growth in an Era of Epic Disruption; Accenture Chemicals: London, UK, 2018.

15. Prudencio, A.A.; Coxon, M.; Boer, E.D.; Ocampo, D.D.; Kadocsa, A.; Mühlreiter, B.; Niel, J.V. Digital Manufacturing-Escaping Pilot Purgatory; Digital McKinsey: Chicago, IL, USA, 2018.

16. Sivrikaya, S.A.; Bhattacharya, C.B. Where Digitalization Meets Sustainability: Opportunities and Challenges; Springer: Heidelberg, Germany, 2017; pp. 37-49.

17. McKinsey \& Company. Unlocking Success in Digital Transformations. Available online: https:/ /www.mckinsey.com/businessfunctions/organization/ our-insights/unlocking-success-in-digital-transformations (accessed on 1 March 2020).

18. MIT Sloan Management Review. The Convergence of Digitalization and Sustainability by Kiron, D. and Unruh, G. Available online: https:/ / sloanreview.mit.edu/article/the-convergence-of-digitalization-and-sustainability/ (accessed on 2 March 2020).

19. Abunadi, I. Enterprise Architecture Best Practices in Large Corporations. Information 2019, 10, 293. [CrossRef]

20. Cameron, B.; Malik, N. A Common Perspectives on Enterprise Architecture; Architecture and Governance Magazine: Austin, TX, USA, 2013; Issue 9-4; pp. 11-17.

21. Rogers, C. Proposed Enterprise Architecture Solutions for Industry 4.0 Manufacturing Simulation Information Assets Based on TOGAF; University of Denver University College: Denver, CO, USA, 2016.

22. Goerzig, D.; Bauernhansl, T. Enterprise architectures for the digital transformation in small and medium-sized enterprises. Procedia CIRP 2018, 67, 540-545. [CrossRef]

23. Urbaczewski, L.; Mrdalj, S. A comparison of enterprise architecture frameworks. Inf. Syst. J. 2006, 7, 18-23.

24. Zachman International. The Concise Definition of the Zachman Framework by John A. Zachman. Available online: https: / / zachman.com/about-the-zachman-framework (accessed on 2 March 2020).

25. North Atlantic Treaty Organization. NATO Architecture Framework Version 4. Available online: https://www.nato.int/cps/en/ natohq/topics_157575.htm (accessed on 2 March 2020). 
26. The University of Minnesota. Enterprise Architecture. Available online: https://it.umn.edu/experts-communities/enterprisearchitecture (accessed on 2 March 2020).

27. U.S. Department of Defense CIO. The DoDAF Architecture Framework Version 2.02.. Available online: https://dodcio.defense.gov / Library/DoD-Architecture-Framework/ (accessed on 2 March 2020).

28. Office of Management and Budget. The Common Approach to Federal Enterprise Architecture; Executive Office of the President of the United States: Washington, DC, USA, 2012.

29. Department of the Treasury. Treasury Enterprise Architecture Framework; United States Department of the Treasury: Washington, DC, USA, 2000.

30. The Open Group. The TOGAF Standard, Version 9.2, TOGAF Part I: Introduction. Available online: https://pubs.opengroup org/architecture/togaf9-doc/arch/chap01.html (accessed on 2 March 2020).

31. The Open Group. The TOGAF Standard, Version 9.2, Introduction to the ADM. Available online: https://pubs.opengroup.org/ architecture/togaf9-doc/arch/chap04.html (accessed on 2 March 2020).

32. Ansyori, R.; Qodarsih, N.; Soewito, B. A systematic literature review: Critical Success Factors to Implement Enterprise Architecture. Procedia Comput. Sci. 2018, 135, 43-51. [CrossRef]

33. Uysal, M.P.; Sogut, M.Z. An integrated research for architecture-based energy management in sustainable airports. Energy 2017, 140, 1387-1397. [CrossRef]

34. Masuda, Y.; Shirasak, S.; Yamamoto, S.; Hardjono, T. Architecture Board Practices in Adaptive Enterprise Architecture with Digital Platform: A Case of Global Healthcare Enterprise. Int. J. Enterp. Inf. Syst. 2018, 14, 1-20. [CrossRef]

35. Haghighathoseini, A.; Bobarshad, H.; Saghaf, F.; Rezaei, M.S.; Bagherzadeh, N. Hospital Enterprise architecture framework (Study of Iranian University Hospital Organization). Int. J. Med. Inform. 2018, 114, 88-100. [CrossRef] [PubMed]

36. Qurratuaini, H. Designing enterprise architecture based on TOGAF 9.1 framework. In Proceedings of the International Conference on Engineering and Applied Technology, Mataram, Indonesia, 29-30 November 2017; pp. 1-11.

37. Cooper, G.; Kosasi, S.; Sulsatri, K. Enterprise Architecture: Key to Successful Digital Business Transformation. In Proceedings of the 1st International Conference on Cybernetics and Intelligent System (ICORIS), Bali, Indonesia, 22-23 August 2019; pp. 156-161.

38. Verdouw, C.; Sundmaeker, H.; Tekinerdogan, B.; Conzon, D.; Montanaro, T. Architecture framework of IoT-based food and farm systems: A multiple case study. Comput. Electron. Agric. 2019, 165, 104939. [CrossRef]

39. Lee, S.; Oh, S.W.; Nam, K. Transformational and Transactional Factors for the Successful Implementation of Enterprise Architecture in Public Sector. Sustainability 2016, 8, 456. [CrossRef]

40. Keller, W.; Bette, N. Shaping digital sustainable development in chemical companies. J. Bus. Chem. 2019, 1, 9-18.

41. World Commission on Environment and Development (WCED). Our Common Future. Available online: https://sustainabledevelopment. un.org/content/documents/5987our-common-future.pdf (accessed on 6 March 2020).

42. Ehrenfeld, J.R. Sustainability by Design: A Subversive Strategy for Transforming Our Consumer Culture; Yale University Press: New Haven, CT, USA, 2009.

43. Responsible Care American Chemistry. Available online: https://responsiblecare.americanchemistry.com/ (accessed on 3 March 2020).

44. Together for Sustainability. Available online: https://tfs-initiative.com/ (accessed on 3 March 2020).

45. Chemie3. Available online: https://www.chemiehoch3.de/de/home.html (accessed on 3 March 2020).

46. PACE. Platform for Accelerating the Circular Economy. Available online: https://pacecircular.org/ (accessed on 3 March 2020).

47. AEPW. Alliance to End Plastic Waste. Available online: https:/ / endplasticwaste.org/ (accessed on 3 March 2020).

48. Mensink, M. 2019 Sustainability Progress Report of the European Chemical Industry Council; European Chemical Industry Council: Brussels, Belgium, 2019.

49. World Business Council for Sustainable Development (WBCSD). Chemical Sector SDG Roadmap; WBCSD: Geneva, Switzerland, 2018.

50. Tabrizi, B.; Lam, E.; Girard, K.; Irvin, V. Digital Transformation Is Not About Technology. Harv. Bus. Rev. 2019, 13, 1-6.

51. Westerman, G.; Calméjane, C.; Bonnet, D.; Ferraris, P.; McAfee, A. Digital Transformation: A Roadmap for Billion-Dollar Organizations; MIT Center for Digital Business and Capgemini Consulting: Cambridge, MA, USA, 2011.

52. Kramer, J.P.; Nellen, J.; Schrapers, M.; Cruz, A. Digital Transformation in the Workplace of the European Chemicals Sector; Prognos AG: Brussels, Belgium, 2019.

53. McKinsey \& Company Insights. Digital in Chemicals: From Technology to Impact. Available online: https:/ / www.mckinsey. com/industries/chemicals/our-insights/digital-in-chemicals-from-technology-to-impact (accessed on 3 March 2020).

54. Carpi, R.; Littmann, A. Chemicals Manufacturing 2030+: More of the Same ... but Different; McKinsey \& Company: Lisbon, Portugal, 2020.

55. Industry Week. Take the Value-Stream Walk: Presentation by Jim Womack. Available online: https://www.industryweek.com/ operations/continuous-improvement/video/21963618/take-the-valuestream-walk-presentation-by-jim-womack (accessed on 3 March 2020).

56. S A Partners. Transform Model: Assess. Available online: https://sapartners.com/transform-model-assess/ (accessed on 3 March 2020).

57. Dombrowski, U.; Krenkel, P.; Ebentreich, D. Link mechanisms within the Lean Enterprise. Procedia CIRP 2016, 57, 601-606. [CrossRef] 
58. Tăucean, I.M.; Tămăsilă, M.; Ivascu, L.; Miclea, S.; Negrut, M. Integrating Sustainability and Lean: SLIM Method and Enterprise Game Proposed. Sustainability 2019, 11, 2103. [CrossRef]

59. Schreiber, B.; Romanus, W.; Lee, Y. Integrating Lean Principles into Digital Transformation; Arthur, D., Ed.; Little: Brussels, Belgium, 2017.

60. EA Pad. The EA3 Cube Approach. Available online: https:/ / eapad.dk/ea3-cube/overview/ (accessed on 3 March 2020).

61. Visual Paradigm Software. Working with TOGAF ADM Guide-through. Available online: https:// circle.visual-paradigm.com/ docs/togaf-adm-guide-through/working-with-togaf-adm-guide-through/ (accessed on 3 March 2020).

62. The Open Group. The TOGAF Standard, Version 9.2. 5. Preliminary Phase. Available online: https://pubs.opengroup.org/ architecture/togaf92-doc/arch/chap05.html (accessed on 5 March 2020).

63. The Open Group. Canadian Government Business Transformation Enablement Program (BTEP). Available online: https: / / pubs.opengroup.org/architecture/togaf9-doc/arch/chap26.html (accessed on 6 March 2020).

64. John Elkington. The Triple Bottom Line: Does It All Add up. Enter the Triple Bottom Line. Available online: https://www. johnelkington.com/archive/TBL-elkington-chapter.pdf (accessed on 6 March 2020). 